\title{
Radiative transfer code: Application to the calculation of PAR
}

\author{
Devred Emmanuel, Dubuisson Phillipe and Chami Malik \\ Laboratoire Interdisciplinaire des Sciences de l'Environnement, Maison de la recheche, 32, Avenue Foch B.P. \\ 59,62930 Wimereux, France.e-mail: devred@loalit.univ-littoral.fr
}

The production of carbon in the ocean, the so-called primary production, depends on various physicobiological parameters: the biomass and nutrient amounts in oceans, the salinity and temperature of the water and the light available in the water column. We focus on the visible spectrum of the solar radiation defined as the Photosynthetically Active Radiation (PAR). We developed a model (Chami et al. 1997) to simulate the behavior of the solar beam in the atmosphere and the ocean. We first describe the theoretical basis of the code and the method we used to solve the radiative transfer equation (RTE): the successive orders of scattering (SO). The second part deals with a sensitivity study of the PAR just above and below the sea surface for various atmospheric conditions. In a cloudy sky, we computed a ratio between vector fluxes just above the sea surface and spherical fluxes just beneath the sea surface. When the optical thickness of the cloud increases this ratio remains constant and around 1.29. This parameter is convenient to convert vector flux at the sea surface as retrieved from satellite to PAR. Subsequently, we show how solar radiation as vector flux rather than PAR leads to an underestimate of the primary production up to $40 \%$ for extreme cases.

\section{Introduction}

The production of carbon in the ocean, the so-called primary production, depends on various physico-biological parameters: the biomass and nutrient amounts in the ocean, the salinity and temperature of the water and the light available in the water column. We focus on the visible spectrum of the solar radiation, defined as the Photosynthetically Active Radiation (PAR). In this paper, we present the radiative transfer code we have developed to compute the PAR and a first application regarding the behavior of PAR in a cloudy atmosphere.

\section{Overview of underwater radiative transfer code}

\subsection{Theoretical background}

The resolution of the radiative transfer equation (RTE) allows the determination of the radiance at each point of a horizontally homogeneous space. Deuze et al (1989) solves the RTE using the successive orders of scattering. We define in figure 1 the geometrical conditions. The radiance, $L$, is expanded in Fourier series to remove the azimuthal components:

$$
L(\mu, \phi)=\sum_{s=0}^{N}\left(2-\delta_{0 s}\right) \cos \left(s\left(\phi-\phi_{0}\right)\right) L^{(s)}(\mu) .
$$

With $\mu=\cos \theta$, where $\theta$ and $\phi$ are respectively the zenith and azimuth direction of the radiance, $\phi_{0}$ is the azimuth of the sun, $s$ the order of expansion of the Fourier series, $\delta_{\{0 s\}}$ Kronecker symbol $\delta_{\{0 s\}}=1$ if $s=0, \delta_{\{0 s\}}=0$ if $s(0)$ and $L(s)$ is the radiance at the order $s$ of the Fourier expansion. We get the spherical flux by integrating the radiance over the whole direction $\phi$ and $\mu$. We notice that the expansion in Fourier series can be stopped at $s=0$ due to the integration of the cosine function (even function) over a period when $s$ is up to 0 . Finally the PAR is

Keywords. PAR; cloud coverage; primary productivity. 


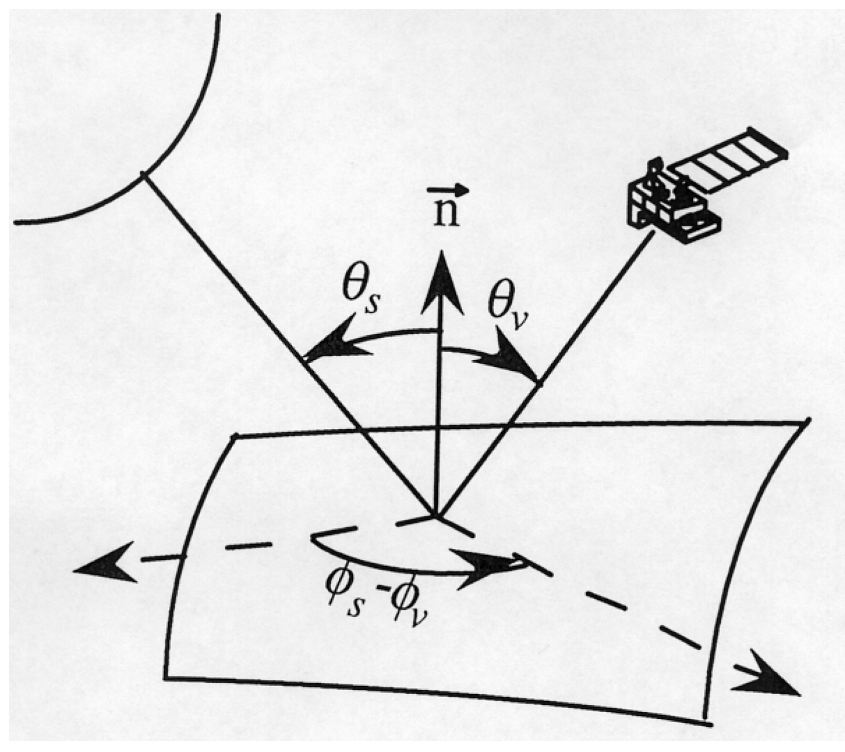

Figure 1. Geometrical conditions.

obtained by integration of the radiance over the spectral range $400 \mathrm{~nm}$ to $700 \mathrm{~nm}$

$$
P A R=\int_{\lambda} \int_{\mu} L(\mu) \mathrm{d} \mu \mathrm{d} \lambda \text { for } s=0\left(W \cdot m^{-2}\right) .
$$

In the case of primary scattering, we obtain a simplified RTE:

$$
\frac{\mathrm{d} L_{1 \lambda}\left(\delta_{\lambda} ; \mu\right)}{\mathrm{d} \tau}=L_{1 \lambda}\left(\delta_{\lambda} ; \mu\right)-J_{1 \lambda}\left(\delta_{\lambda} ; \mu\right)
$$

where $\lambda$ is the wavelength, the last term $J_{1 \lambda}$ is a source term (the radiance at the top of atmosphere) and $\delta_{\lambda}$ is the optical thickness of the atmosphere. If we account for multiple scattering, we need to solve a set of $N$ equations similar to (3). The source term $J_{N}$ of the equation $N$ consists of the radiance at the order $N-1$ $\left(L_{N}-1\right)$.

\subsection{Optical parameters of atmosphere and ocean}

The optical properties of the atmospheric and oceanic layers yield the extinction of the radiation beam. Thus, the optical thickness is relied to the extinction coefficient,

$$
\delta_{\lambda}(z)=\int_{0}^{z} c_{\lambda}\left(z^{\prime}\right) \mathrm{d} z^{\prime},
$$

with

$$
c_{\lambda}(z)=a_{\lambda}(z)+b_{\lambda}(z)
$$

where $c_{\lambda}(z)$ is the extinction coefficient, $a_{\lambda}(z)$ and $b_{\lambda}(z)$ are respectively the absorption and the scattering coefficients. The total extinction of the layer is given by,

$$
c_{\lambda, \text { total }}(z)=\sum_{i}\left(a_{\lambda, i}(z)+b_{\lambda, i}(z)\right)
$$

where $a_{\lambda, \text { total }}(z), b_{\lambda, \text { total }}(z)$ and $c_{\lambda \text {,total }}(z)$ represent the total attenuation, scattering and extinction coefficients respectively and $a_{\lambda, i}(z), b_{\lambda, i}(z)$ and $c_{\lambda, i}(z)$ the absorption, scattering and extinction coefficients of the species $i$. In the atmosphere, three components contribute to the extinction of the light; the gaseous molecules, the aerosols and clouds droplets. The molecular scattering is computed from Rayleigh theory, and the gaseous transmittance for ozone, oxygen and water vapor from Leckner (1978), with absorption coefficients for these gases taken from Gregg and Carder (1990). The cloud properties are computed with Mie theory from standard cloud types referenced according to their droplet size. We consider 11 kinds of clouds described in table 1 (Stephens 1978 and Brogniez et al 1995). In a similar way, the Mie theory is used to compute the optical properties of the aerosols. Their parameters are given by the World Meteorological Organization (WMO 1986). They are a mixture of basic components: soot, dust-like, water soluble and oceanic. Four classes of aerosol are defined with respect to their origin: continental, urban/ industrial, maritime and stratospheric (table 1).

In the ocean, there are four components separated according to their optical properties. Figure 2 illustrates the behavior of absorption and scattering coefficients for each component. The absorption of pure sea water, $a_{w}$, (Pope and Fry 1997) increases with the wavelength and the scattering coefficient, $b_{w}$, exponentially decreases; the scattering coefficients are tabulated from Morel (1974). The phytoplankton abundance and optical properties are described throughout as chlorophyll " $a$ " pigment optical properties. Regarding the absorption, many biooptical models exist. The model of Morel (1991) suggests the following fit for the absorption of various algae species,

$$
a_{\text {chla }}(\lambda)=0.06 a_{\text {chla }}^{*}(\lambda) C^{0.65} .
$$

with $\lambda$ wavelength (nm), $C$ concentration of chlorophyll " $a$ " $\left(\mathrm{mg} \mathrm{m}^{-3}\right)$ and $a_{\text {chla }}^{*}$ a nondimensional chlorophyll-specific absorption coefficient. However, the computer code enables inclusion of absorption coefficient of algae species measured in situ by the users. The scattering coefficients of chlorophyll pigments, $b_{\text {chla }}$, are very difficult to measure experimentally. Usually, we use a bio-optical model to derive $b_{\text {chla }}$ from the concentration of chlorophyll " $a$ " pigment. In this work we selected the Gordon and Morel (1983) model,

$$
b_{\text {chla }}(\lambda)=\left(\frac{550}{\lambda}\right) 0.30 C^{0.62} .
$$

The yellow substances are assumed to be absorbent material. The absorption coefficient $\left(a_{y s}\right)$ exponentially decreases with wavelength (Bricaud et al 1981) with the exponential coefficient depending on the water type. The non-chlorophyll suspended matters 
Table 1. Clouds and aerosol characteristics.

\begin{tabular}{|c|c|c|c|}
\hline \multicolumn{4}{|c|}{ Cloud model droplet distribution } \\
\hline Cloud type & Mode radius $(\mu \mathrm{m})$ & Effective radius $(\mu \mathrm{m})$ & Liquid water content $\left(\mathrm{g} \mathrm{m}^{-3}\right)$ \\
\hline Stratus I & 3.50 & 5.89 & 0.22 \\
\hline Stratus II & 2.25 & 4.18 & 0.05 \\
\hline Stratocumulus I & 3.50 & 5.36 & 0.14 \\
\hline Stratocumulus II & 7.50 & 9.84 & 0.47 \\
\hline Nimbostratus & 3.50 & 9.27 & 0.50 \\
\hline Altostratus & 4.50 & 6.16 & 0.28 \\
\hline Fair Weather Cumulus & 5.50 & 12.1 & 1.00 \\
\hline Cumulonimbus & 6.00 & 31.23 & 2.50 \\
\hline \multicolumn{4}{|c|}{ Ice cloud parameter } \\
\hline Cloud type & \multicolumn{2}{|c|}{ Crystal type } & Dimensions $(\mu \mathrm{m})$ \\
\hline Cirrus I & \multirow{2}{*}{\multicolumn{2}{|c|}{$\begin{array}{l}\text { Hexagonal plate } \\
\text { Hexagonal column }\end{array}$}} & $15 / 125$ \\
\hline Cirrus II & & & $240 / 30$ \\
\hline \multicolumn{4}{|c|}{ Aerosol model distribution } \\
\hline Aerosol model & Aerosol components & Percentage by aerosol & Size distribution \\
\hline Continental & $\begin{array}{l}\text { Dust-like } \\
\text { Water-soluble } \\
\text { Soot }\end{array}$ & $\begin{array}{c}70 \\
29 \\
1\end{array}$ & Log normal \\
\hline Urban/Industrial & $\begin{array}{l}\text { Dust-like } \\
\text { Water-soluble } \\
\text { Soot }\end{array}$ & $\begin{array}{l}17 \\
61 \\
22\end{array}$ & Log normal \\
\hline Maritime & $\begin{array}{l}\text { Oceanic } \\
\text { Water-soluble }\end{array}$ & $\begin{array}{c}95 \\
5\end{array}$ & Log normal \\
\hline Stratospheric & Sulphuric acid droplets & 100 & Modified gamma \\
\hline
\end{tabular}

are so variable in composition and concentration in coastal waters that it is very difficult to derive a biooptical model. We compute their absorption and scattering coefficients from Mie theory using a refractive index equal to 1.20 and a Junge power law for the size distribution. The particle size ranges from $0.01 \mu \mathrm{m}$ to $50 \mu \mathrm{m}$.

\section{Validation of the code}

\subsection{Atmosphere layer}

For the atmospheric component, we compare our code (Successive orders code, SO) with a reference atmospheric model (Global Atmospheric Model, GAME, Dubuisson et al 1996). We compute the scalar irradiance at the sea surface for various atmospheric conditions: Rayleigh atmosphere, cloudy atmosphere (stratus II). The results are plotted in figure 3 . We obtain a very good agreement between both models even for the strong optical thicknesses, the error is within $1 \%$. However, the computing time for optical thicknesses greater than 30 is getting very high due to the numerous scattering events.

\subsection{Ocean layer}

We compare the euphotic depth computed with the SO code for case 1 water (Morel and Prieur 1977) with measurements published by Morel (1988). The error between both measurements and model (see table 2) is maximum for chlorophyll " $a$ " concentration of $3 \mathrm{mg}$ $\mathrm{m}^{-3}$ and reaches $8 \%$ For lower concentration of chlorophyll " $a$ " the difference is quite small and about $3 \%$ (typically $3 \mathrm{~m}$ for $\left[\right.$ chla] $=0.1 \mathrm{mg} \mathrm{m}^{-3}$ ). The model for chlorophyll " $a$ " absorption is derived from a fit carried out on many measurements, so we have a natural variability of the absorption coefficient, which may explain this observed difference. But, the results between the model and the measurements are quite good.

\section{Sensitivity of PAR to the cloud coverage}

One of the objectives in the study of primary production is to produce annual budgets. Since clouds play a role in the radiative budget they should have a significant influence on the primary production. Moreover, the satellite remote sensing techniques for 
a)

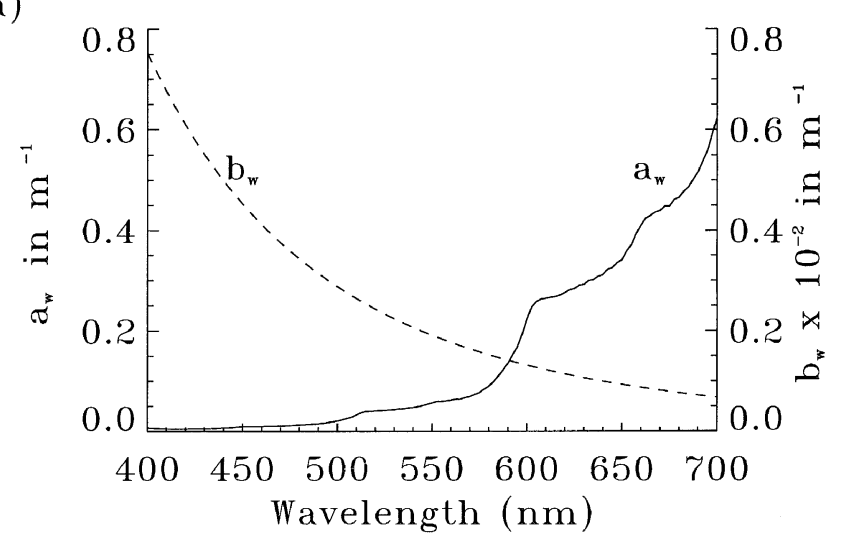

b)

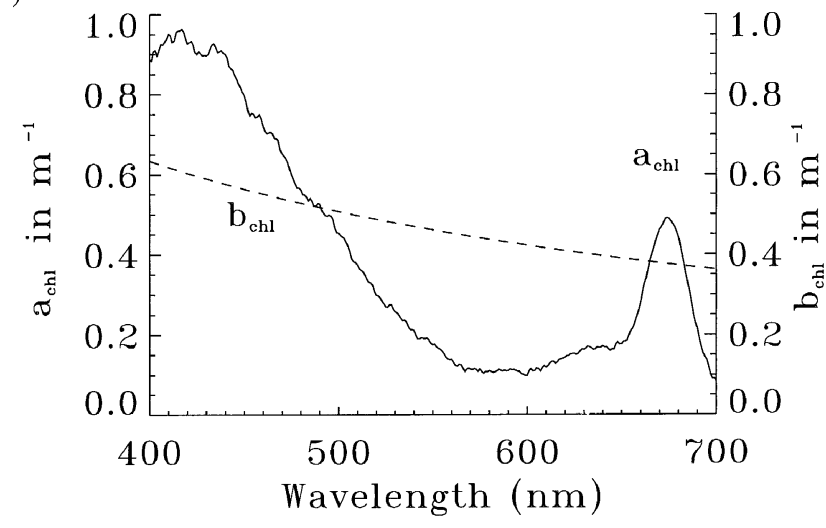

c)

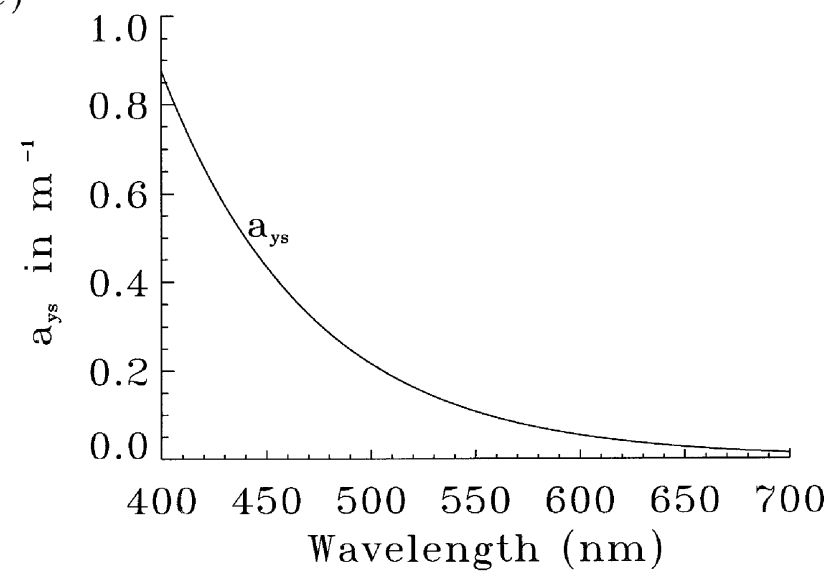

Figure 2. Absorption (solid line) and scattering (dashed line) coefficient for a) pure sea water, b) suspended chlorophyllous matter and c) yellow substances.

the retrieval of geophysical parameters are dependent of the cloud coverage. We then performed a sensitivity study of PAR to cloud coverage (figure 4). First the type of cloud was studied. Figure 4(a) clearly shows that the PAR is insensitive to the features of the cloud (optical properties and averaged mode radius of the size droplet). Therefore we selected a stratus II (see table 1a) to predict the signal. The critical parameter for attenuation of PAR in the water column is then

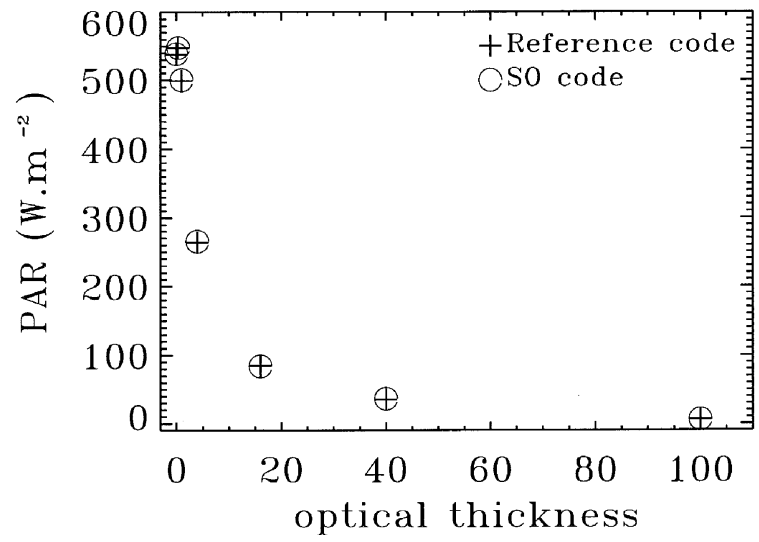

Figure 3. Comparison between a reference code (GAME) and the SO code for a cloudy atmosphere.

the optical thickness of the cloud $\left(\tau_{c}\right)$ (figure $4(\mathrm{~b})$ ). The ratio between optical thickness and PAR is not the same at a given depth: $\tau_{20} / \tau_{10}$ but the ratio between $\mathrm{PAR}_{\tau_{20}}$ and $\mathrm{PAR}_{\tau_{10}}$ is 0.587 (instead of 0.5 ). The variation of the PAR is not a linear function of the optical thickness. Moreover, for a constant ratio of optical thickness the PAR does not decrease in the same way at a given depth. For example the ratio between the optical thicknesses 10 and 5 and between thicknesses 20 and 10 is 2, while computing the ratio between PAR at these optical thicknesses for both cases we respectively obtain 0.587 and 0.664 (at $10 \mathrm{~m}$ depth). So, the cloud abundance is a critical parameter on estimation of PAR.

One way to know the PAR in the ocean at large temporal and spatial scale is to use remote sensing methods. These methods are based on the vector irradiances measured at the sea surface $\left(F_{v}\right)$ whatever the atmospheric conditions, where

$$
F_{v}=\int_{\mu} L(\mu) \mu \mathrm{d} \mu
$$

with $\mu$ the cosine of the zenith angle that ranges from -1 to 1 .

From the SO code we compute the ratio between the vector flux integrating over the range 400 to $700 \mathrm{~nm}$ just above the sea surface and the PAR just beneath the sea level $\left(\operatorname{PAR}\left(0^{-}\right)\right)$for various sky conditions and solar zenith angles $\left(\mathrm{SZA}=10^{\circ}, 30^{\circ}\right.$ and $45^{\circ}$, figure 5$)$. We first note that the integrated vector fluxes are always smaller than PAR whatever the

Table 2. Euphotic depth computed from Morel (1988) and with the $S O$ code.

\begin{tabular}{lcccccc}
\hline CHLa (mg.m-3) & 0.1 & 0.3 & 1. & 3. & 10. & 30. \\
\hline Morel (1988) & 95 & 64 & 39 & 24 & 14 & 8 \\
SO code & 98 & 62 & 37 & 22 & 13 & 8 \\
Error $(\%)^{*}$ & 3.1 & 3.1 & 5.1 & 8.3 & 7.1 & 0 \\
\hline
\end{tabular}

${ }^{*}$ Error $=((\mathrm{SO} /$ Morel $)-1){ }^{*} 100$ 
a)

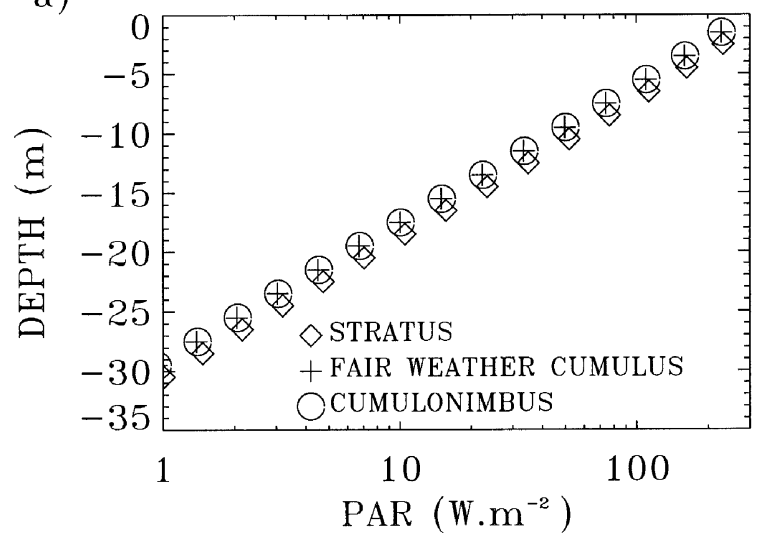

b)

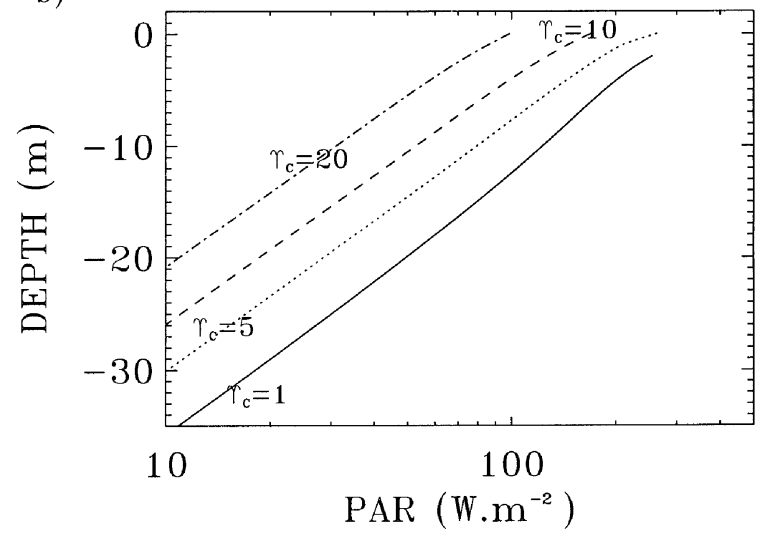

Figure 4. a) Distribution of $\operatorname{PAR}\left(\mathrm{W} \cdot \mathrm{m}^{-2}\right)$ on the water column for 3 types of clouds: stratus (diamond), fair weather cumulus (cross) and cumulonimbus (circle); b) distribution of PAR on the water column in a cloudy atmosphere for various optical thicknesses.

atmospheric conditions, as shown in figure 5. This can be explained by the contribution of the cosine for the vector fluxes. We notice that from an optical thickness of five this ratio is still the same. This result can be explained by the extinction of the direct solar beam in favour of the isotropic light. The beam has undergone many scattering events within the cloud so that the radiance exiting the cloud has lost its main direction. We emphasize on the fact that it is important to convert the integrated vector flux into PAR while we work with remote sensing method techniques because satellites are able to derive vector fluxes rather than scalar fluxes. Our results suggest that considering only satellite products to assess primary production leads to an underestimation of photosynthetic productivity (PAR is greater than the integrated vector fluxes, as we see in figure 5). For example, we computed the primary productivity (equation 10) from the model of Platt et al (1980) for three atmospheric situations clear sky with a visibility of $23 \mathrm{~km}\left(\tau_{a}=0.2\right)$, a marine haze with a visibility of $1 \mathrm{~km}\left(\tau_{a}=3\right)$ and a cloudy sky $\left(\tau_{c}=20\right)$. The photosynthetic parameters were derived from algae collected in the Straits of Dover in June 1995 (from F. Lizon personal communication). We carried out predictions for a supposed identical physiological state of the cells.

$$
\begin{aligned}
P P^{B}(I)= & B \cdot P_{m}^{B} \times\left(1-\exp \left(-\alpha^{B} I / P_{m}^{B}\right)\right) \\
& \times \exp \left(-\beta^{B} I / P_{m}^{B}\right) .
\end{aligned}
$$

$P P^{B}$ is the primary production $\left(\mathrm{mgC} \mathrm{h}^{-1}\right), P_{m}^{B}$ the maximum photosynthetic rate $\left(\mathrm{mgC}\left(\mathrm{mg} \mathrm{chl}_{a}\right.\right.$ $\left.\left.\mathrm{m}^{-3}\right)^{-1} \mathrm{~h}^{-1}\right), B$ the quantity of biomass $\left(\mathrm{mg} \operatorname{chl}_{a}\right.$ $\left.\mathrm{m}^{-3}\right), I$ the irradiance $\left(\mu\right.$ Eins $\left.\mathrm{m}^{-3} \mathrm{~s}^{-3}\right), \alpha^{B}$ the photosynthetic rate and $\beta^{B}$ the inhibition factor. The values of the parameters are:

$$
\begin{aligned}
& P P^{B}=11.61 \mathrm{mgC}\left(\mathrm{mg} \text { chla } \mathrm{m}^{-3}\right)^{-1} \mathrm{~h}^{-1}, \\
& \alpha^{B}=0.13 \mathrm{mgC}\left(\mathrm{mg} \text { chla } \mathrm{m}^{-3}\right)^{-1} \mathrm{~h}^{-1} \\
& \left(\mu \text { Eins } \mathrm{m}^{-2} \mathrm{~s}^{-1}\right)^{-1} \text {, } \\
& \beta^{B}=0.005 \mathrm{mgC}\left(\mathrm{mg} \text { chla } \mathrm{m}^{-3}\right)^{-1} \mathrm{~h}^{-1} \\
& \left(\mu \text { Eins } \mathrm{m}^{-2} \mathrm{~s}^{-1}\right)^{-1}, \\
& \mathrm{~B}=2.0 \mathrm{mg} \text { chla } \mathrm{m}^{-3} \text {. }
\end{aligned}
$$

We add on the PI curve the fluxes (figure 6: integrated vector flux (circle) and PAR (triangle)) as computed for the various atmospheres. The consequences in term of primary production depend on the depth and the amount of light depending on the cloud coverage. Figure 6(a) shows that in the cloudy sky case the values of PAR are smaller than those in clear sky and the dots are not located on the same area of the curve. It raises different values for the primary production. We estimate the error with

$$
\text { Error }=\left(F_{v} / P A R-1\right) * 100 \text {. }
$$

In clear sky, a difference of $27 \%$ in fluxes leads to an error of $7 \%$ in primary productivity whereas a difference of $40 \%$ in cloudy sky leads to an error of

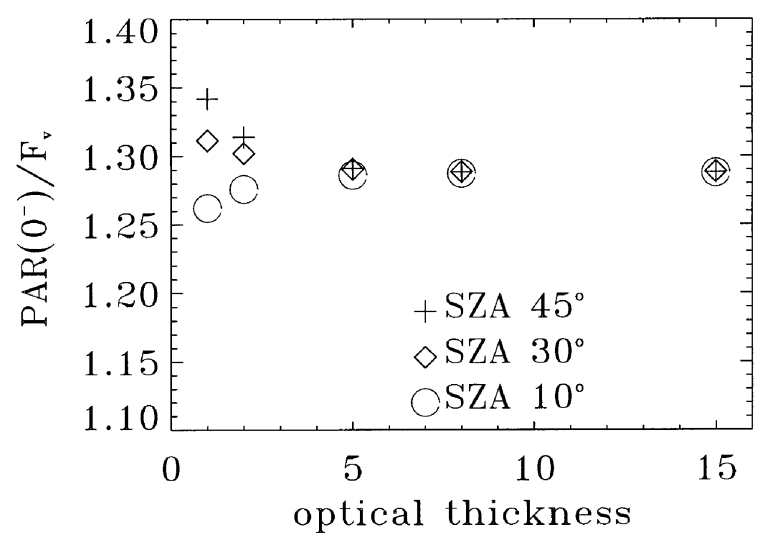

Figure 5. Ratio between the plane flux just above the sea surface and PAR below the sea surface as a function of the optical thickness. 

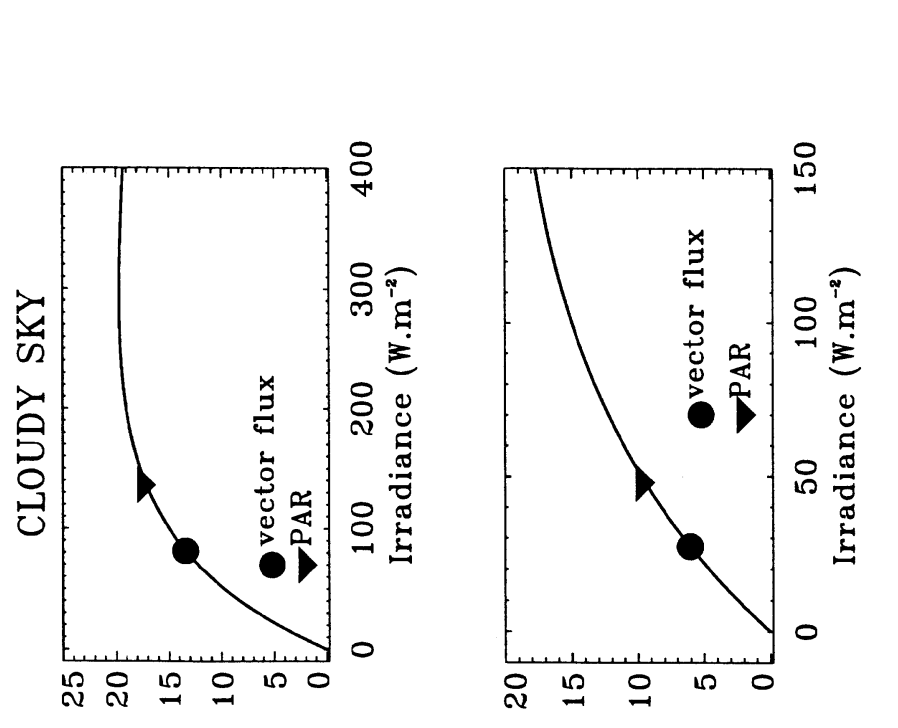

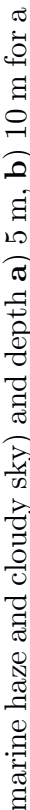
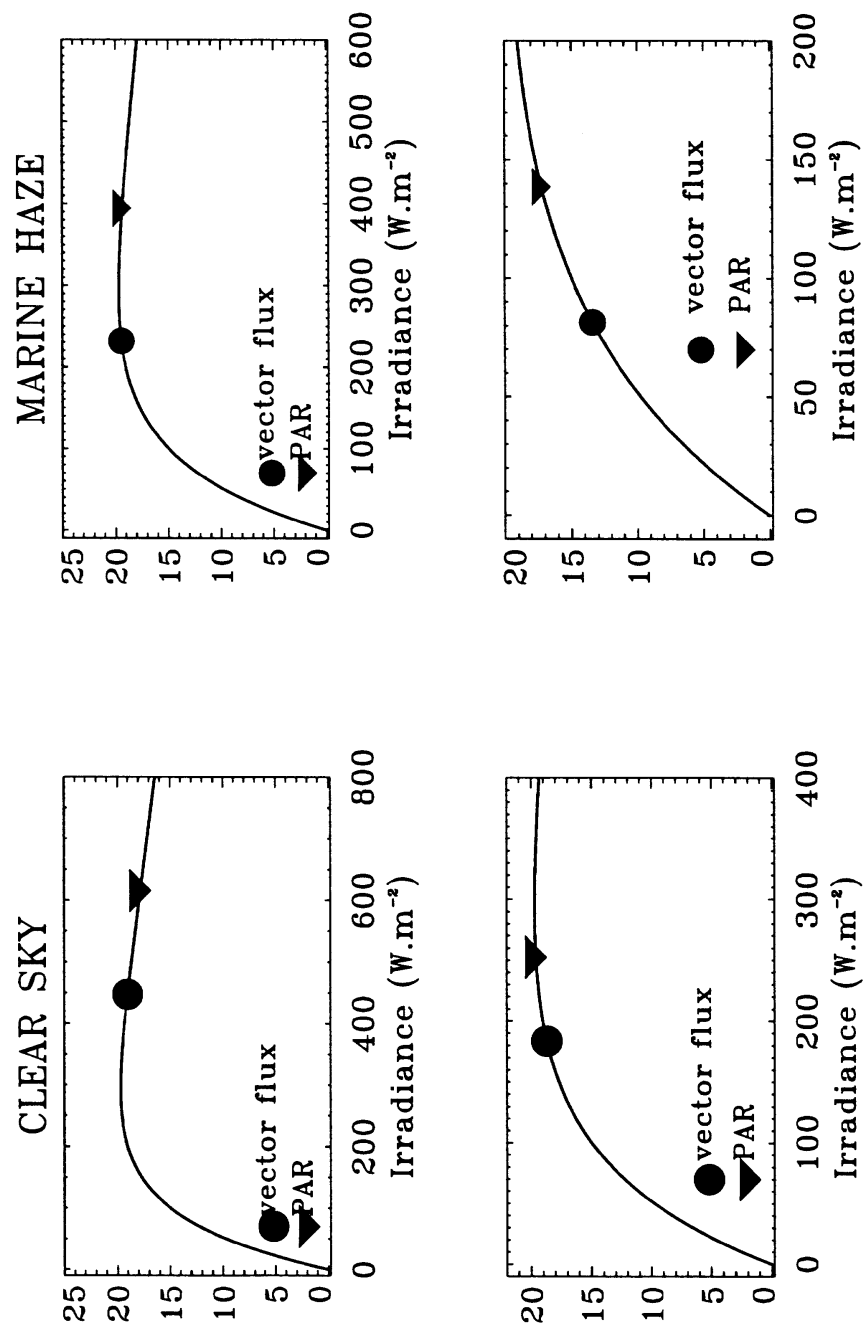

$\left({ }_{1} 4 \cdot 0^{8 ิ น}\right){ }_{8} \mathrm{dd}$

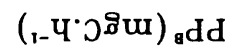

శ

o

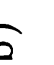


$20 \%$ in primary productivity. In the intermediate case (marine haze) the error is less than $1 \%$ for the primary production because the dots are located in the constant area of the PI curve. Thus, it appears that the error remains less than $20 \%$ for large variability of the atmospheric conditions. A great discrepancy between integrated vector fluxes and PAR does not necessarily involve the same order of variation. In figure $6(\mathrm{~b})$, the energy is smaller than figure 6(a) due to the attenuation of light with depth. The dots are in the linear area of the curve $\left(P P^{B} \approx \alpha^{B} I\right)$ so the error on the estimated primary production is getting more sensitive to the cloud coverage $(22.2 \%$ for marine haze and $36 \%$ for cloudy sky). It is better to consider scalar fluxes near the surface to avoid large error on primary production due to various atmospheric conditions.

\section{Conclusion}

We have developed and tested a radiative transfer code to compute the PAR in the oceans for various atmospheric conditions (cloudy and clear sky, haze). We performed a sensitivity study regarding the behavior of the PAR in the atmosphere and through the air-sea interface. First we showed that the PAR in reaching the sea surface is not dependent of the type of cloud. Secondly, we noticed the non-linearity of the PAR attenuation with respect to the atmospheric conditions and especially in cloudy sky. The integrate vector flux (over the range 400 to $700 \mathrm{~nm}$ ) just above the sea surface can be converted into PAR just beneath the sea surface for remote sensing applications in cloudy atmosphere. This conversion factor is approaching a constant when the optical thickness increases due to the isotropy of the radiation. The conversion factor is a required parameter to derive primary production from satellite remote sensing techniques. The next step of this work will be to estimate the PAR at large spatial and temporal scale (the Straits of Dover over a whole year) using remotely sensed data (METEOSAT) whatever may be the atmospheric conditions. Subsequently, the introduction of ocean color data and PAR in a primary production model will enable estimation of the production of carbon in the channel.

\section{References}

Bricaud A, Morel A, Prieur L 1981 Absorption by dissolved organic matter of the sea (yellow substance) in the UV and visible domains. Limnnol. Oceanogr. 28(5), 816-832

Brogniez G, Buriez J C, Giraud V, Parol F and Vanbauce C 1995 Mon. Weather. Rev 1231025

Chami M, Dilligeard E and Santer R, 1997 A radiative transfer code for the sea atmosphere system; Remote sensing of Ocean and Sea Ice III, Proceedings vol 3222, Earth Surface Remote sensing, Aerospace remote sensing, SPIE EUROPTO

Deuze' J L, Herman M and Santer R 1989 Fourier series expansion of the transfer equation in the atmosphere-ocean system; J. Quant. Spectrosc. Radiat. Transfer 41 N6 pp. 483-494

Dubuisson P, Buriez J C and Fouquart Y 1996 High spectral resolution solar radiative transfer in absorbing and scattering media: application to the satellite simulation; J. Quant. Spectrosc. Radiat. Transfer 55, N1, pp. 103-126

Gordon H R and Morel A 1983 Remote assessment of ocean colour for interpretation of satellite visible imagery. A review (New York: Springer)

Gregg W W and Carder K L 1990 A simple solar irradiance model for cloudless maritimes atmospheres; Limnol. Oceanogr., 35 1657-1675

Leckner B 1978 The spectral distribution of solar radiation at the earth surface-elements of a model; Solar Energy 20 $143-150$

Morel A 1974 Optical properties of pure sea water. pp. 1-24, In Optical aspects of Oceanography. (eds) N G Jerlov and E N Steeman (New York: Academic Press)

Morel A and Smith R C 1974 Relation between total quanta and total energy for aquatic photosynthesis; Limnnol. Oceanogr. 19 n4; pp. 591-600

Morel A and Prieur L 1977 Analysis of variation in ocean color; Limnol. Oceanogr. 22(4) 709

Morel A, 1991b Light and marine photosynthesis: a spectral model with geochemical and climatological implications; Prog. Oceanogr. 26263

Morel A 1988 Optical modeling of the upper ocean in relation to its biogenous matter content; J. Geophys. Res., 93, 10749-10768

Morel A, 1980 In-water and remote measurements of ocean color; Boundary-Layer Meteorology 18 177-201

Platt T, Gallegos C L, Harrison W G 1980 Photoinhibition of photosynthesis in natural assemblages of marine phytoplankton; J. Marine Res. 38 687-701.

Pope R M and Fry E S 1997 Absorption spectrum (380-700 $\mathrm{nm}$ ) of pure water II; Integrating measurements; Appl. Opt., 36 N33, 8710-8723

Stephens G L 1979 Radiation profiles in extended water clouds I; Theory; J. Atmos. Sci. 35 2111- 2122

World Meteorological Organization (WMO, 1986) A preliminary cloudiness standard atmosphere for radiation computation; Report n24; WCP 112 